\title{
DESIGN AND VALIDATION OF A PRODUCT-DRIVEN CONTROL SYSTEM BASED ON A SIX SIGMA METHODOLOGY AND DISCRETE EVENT SIMULATION
}

\author{
Hind El Haouzi*, Jean-françois Pétin, André Thomas \\ CRAN - Faculté des sciences - BP239 - 54506 - VANDOEUVRE les NANCY. \\ This article is an extended paper issuing from the selected IESM07 conference paper.
}

\begin{abstract}
Recent trends in industry towards autonomous and just-in-time production systems, and the latest developments in Auto-ID technologies, have created new opportunities for enhancing reactivity and agility on the shop floor. To take advantage of these opportunities, a Product Driven System (PDS) concept can be seen as an innovative control concept that advocates that a product can be an active actor throughout its lifecycle by associating the material flow with the product information. We propose a methodological approach that contributes to the design and validation of such a system. More specifically, this work focuses on an infrastructure that satisfies PDS control requirements. The feasibility of our proposed approach was evaluated by the development of an industrial case at the Trane Company using six sigma methodology and discrete event simulation.
\end{abstract}

\section{Keywords}

Product driven control, six sigma, project driven management, discrete event simulation, Auto-id technologies.

\section{Introduction}

Since the 1990s, the mode of production in enterprises has changed from the traditional mass production mode into the mass customization production mode to meet increasing global market competition. Consequently, best practice in manufacturing system control has moved away from traditional centralized approaches based on Manufacturing Planning and Control Systems (MPCS) (Vollman et al., (1988)), where decision making is hierarchically broadcast from the higher decisional levels down to the operational units, to a hybrid control approach that provides more autonomy and responsibility to staff. Just-in-Time (JiT) applications, such as the "Kanban" system, are examples of such practices. The changes outlined above have created a dramatic challenge for control management. Control systems have trended towards systems where local and autonomous decision making is possible. This fact removes any "inertia" induced by different levels in centralized control structures, improves reactivity, and simplifies the decision-making process on the shop floor.

However, JiT applications face many challenges. The first challenge is low visibility on the shop floor. A supply chain manager can only control inputs and outputs from "black boxes". The second challenge is that optimality cannot be guaranteed because human operators make decisions with only a partial view of the shop floor. In recent research, new processes or concept automation have appeared that ensure visibility and traceability, and provide support tools for decision making. Among these concepts, product-driven control is innovative in that the product can be an active actor throughout its lifecycle, taking advantage of the emerging opportunities presented by Auto-ID technologies.

The main goal of this work was to propose a methodological approach to design a Product Driven System (PDS) and validate its feasibility and efficiency using a real industrial case. Moving from the customer requirement and identification of efficiency metrics to the design and implementation of PDS solutions, our proposed approach is based on the six sigma method and discrete event simulation. We were particularly interested in the Trane Company, which provides indoor comfort systems and comprehensive facility solutions for residential, commercial, and industrial building needs. The Trane Company is represented all over the world, and has 27 operational sites. Pushed on by increasing

\footnotetext{
* Corresponding author. Email: Hind.elhaouzi@cran.uhp-nancy.fr
} 
technological innovation and the request for products with increasingly short lifecycles, the company tends to standardize processes according to Demand Flow Technology (DFT) (Costanza, (1996)), and optimizes its production through the PDS concept, thus providing more agility and competitiveness.

Section 2 provides a basic understanding of the DFT and PDS concepts and, in particular, shows that the Radio Frequency Identification (RFID) layout has a major impact on the efficiency of a PDS control program. Section 3 proposes generic guidelines for capturing customer requirements, defining efficient indicators, designing a candidate RFID layout, and then validating the solution using discrete event simulation. The application of our proposed approach to the Trane Company is discussed in Section 4. We conclude with an assessment of our achievements and perspectives, and identify our limitations.

\section{PDS in a DFT context}

It should be noted that the background to this work concerns an assembly shop floor. The organization of such a shop floor is often composed of one or more assembly lines and several feeders (see Figure $1)$.

The first way to control such a system is to use Enterprise Resource Planning (ERP, a centralized system), which provides global predictive periodical schedules for the assembly line on the one hand, and for the feeders on the other hand. The Master Production Schedule (MPS) induces a pushed flow strategy that takes into account the mean manufacturing cycle time. This fact gives rise to a resulting inventory at synchronization points that are traditionally enlarged to constitute safety stock, especially useful when disturbing events occur after stock release.

A first palliative solution to reduce any Work In Process (WIP) is to remove the synchronization decision from the centralized system (ERP) and use the "Kanban" system to control the feeders. To be certain that a required component (semi-finished) arrives at the correct time, thus avoiding a shortage, the "in-process Kanban" (IPK) system, which can be seen as a replenishment system, is implemented between the assembly line and each feeder. This type of organization (physical structure and control) is promoted by the Demand Flow Technology (DFT) approach. The DFT is a JiT methodology that leads to a strictly similar assembly line organization, as its objective is to optimize production through processes standardization.

From a theoretical point of view, a basic two-bin system involving only a single part in the IPK is sufficient to implement such an organization. However, in the case of disturbances and cycle time variations, this goal is obviously unrealistic, and a safety stock level must still be maintained. The visibility horizon is closely linked to the IPK level because the activation of a feeder Kanban is mainly based on local information, which is available at the synchronization point without any knowledge of events that are occurring at upstream workstations (for the assembly line, as well as for the feeders).

To improve visibility and to facilitate the adaptation of local decisions, there is a strong need for JiT information associated with materials flow. This assumes that important events related to the products should be stored and made available to trace the system behaviour in real time. In the recent research, a product's role can be more than just providing information; it can involve making a local decision. One concept of this new way of control is Product Driven System (PDS). PDS is a holonic paradigm specialization, proposed by McFarlane at the University of Cambridge, UK (McFarlane et al., (2003)), that a product can be an active actor throughout its lifecycle by initiating an eventual decision-making stage (to react to a product event), and participating in this way towards system control. In fact, the PDS paradigm aims to investigate challenges, trends, and open issues related to the potential active role of the product in a cybernetic loop. This paradigm has become realistic because of increasing capabilities of infotronics technology (e.g., RFID and wireless technologies).

RFID is a suitable technology for providing product information, storage, and communication, using wireless technology for the tagging and identification of materials and components. All RFID systems contain a reader and a transponder. The transponder is the data carrier part of the RFID system. The 
RFID reader's tasks are to power, read, write, and handle the communication to and from the transponder. Among the many challenges of RFID (Wu et al., (2005)), the cost of integration with legacy systems (e.g., the ERP and Manufacturing Execution System) through middleware, and the interoperability standard (e.g., EPCglobal, (2005), ISO/IEC 18000, (2004)) have been highlighted. The widespread industrial adoption of this technology today is limited by the capability to quantify and to evaluate the benefits of an RFID system through pertinent business cases.

Except for geolocalization wireless technologies, whose costs and functionalities are not justified in the case of a discrete processes, traditional RFID technologies lead to discrete information reporting induced by discrete reader points (see Figure 2). In the DFT context involving assembly line synchronization, the reading points layout has an impact on the reactivity and anticipation capability of the decision-making process. Indeed, if the reader is laid down at the beginning of the main assembly line (Position 1 in Figure 2), it means that the decision will be made with advanced anticipation. Consequently, this will lead to a high IPK level. (This situation is equivalent to centralized control.) If the reader is laid down at the IPK location (Position 2), it means that the decision is made with no reaction capability against perturbing events because of too short visibility.

Consequently, the reader layout can be considered as being the core of PDS control engineering. A methodological approach is needed to choose the most efficient layout of the readers according to control requirements and to validate the candidate solution according to performance indicators.

In this way, IMS-NoE, a special interesting group (Cavalieri et al., (2003), Valckenaers et al., (2006)), has shown that simulation-based benchmarking of complex manufacturing systems remains the means to show the efficiency of plant wide control organizational issues before their deployment for practical purposes. The development of a PDS test-bed must be based on an initial clear definition of performance indicators that the PDS is expected to improve. This requires an understanding of the customer's requirements and an identification of the level of performance that is required to satisfy, and even delight, the customer. To answer this objective, six sigma seems to be the most adapted methodology, because it offers an array of interesting quality tools in addition to the reported financial results, has more advanced data analysis tools, focuses on customer concerns, and uses project management tools and methodology (Anbari, (2002)). Moreover, the six sigma lifecycle is widely accepted by both the scientific and industrial communities.

\section{An overview of the literature on the six sigma approach and discrete event simulation}

The six sigma method is a project-driven management approach used to improve an organization by continually reducing the number of defects to as low as 3.4 parts per million. It uses a normal distribution and the strong relationship between product nonconformities, or defects. Numerous books and articles have provided the basic concepts and benefits of the six sigma method (Harry and Schroeder, (2000), Hoerl (2001)).

Dating back to the mid 1980s, the application of the six sigma method has allowed many organizations to sustain their competitive advantage by integrating their knowledge of their process with statistics, engineering, and project management (Anbari, (2002)). The challenges and realities in implementing the six sigma method successfully are immense. However, we can outline some of the issues to be solved. The objective of this section is to review and explain different stages of six sigma, its benefits, and the challenges of six sigma practices, and to identify the key factors influencing the successful six sigma project implementation of a PDS.

There are two types of approaches to drive a six sigma project. (1) The DMAIC (Define Measure Analyze Improve Control) methodology, explained below, is used when a product or process is in existence at the company but is not meeting customer specification or is not performing adequately. This methodology is almost universally recognized and is defined as comprising the following five phases: Define, Measure, Analyse, Improve, and Control. Opposite to this, when a process or product does not exist, the Design for Six Sigma (DFSS) methodology is used. Consequently, the integration of our PDS was based on the DFSS approach. 


\subsubsection{Design for a six sigma approach}

The DFSS is comprised of five phases or steps, as shown in Figure 3. The initial three phases focus heavily on understanding customer requirements and identifying the level of performance that is required to satisfy, or even delight, the customer. Once this is understood, the design phase is conducted, followed by the verify phase.

- In the definition phase, the objectives are based on defining the project and scope, while also identifying any constraints and risks.

- In the measurement phase, the object is the voice of the customer. In this phase, the team gains an understanding of the customer's needs and wants. Those needs and wants are then translated into requirements, or Critical to Quality requirements (CTQs), and are prioritized.

- In the analyse phase, key functions are identified and concepts generated and evaluated. The objective is to select the necessary functions and most viable concepts for likely success.

- There are three high-level deliverables from the design phase. The first deliverable is the design of the proposed process. The second is a test design to predict the processes' performance and the actual conduct of the test. The third is the preparation made for a pilot and full-scale deployment.

- Finally, in the verify phase, the main objective is to verify the design's performance and make corrections where needed. Further control plans are often created for the next step of full deployment.

\subsubsection{Obstacles and challenges of using the six sigma method}

This approach was useful in structuring our study and to define a global strategy to deploy PDS and RFID technology. However, in the scientific community, six sigma has many challenges for its logical adoption in enterprise projects. Hoon and Anbari (2006) showed that the most important issues in six sigma are related to strategy, to organizational culture, and to training (the belt program) in the company. Indeed, to ensure the long-term sustainability of the six sigma method, organizations need to analyse and accept its strengths and weaknesses, and properly use six sigma principles, concepts, and tools. In practice, the difficult part of six sigma is to have good data to be able to perform different analyses and statistical calculations and to validate choices, especially when the process to be studied does not already exist. For example, when we use the DFSS method in the verify phase, we need to validate the CTQs and quantify their impact on the process studied. In particular, in our context, the RFID system did not exist, and thus, we could not apply any statistical tools. We need a tool that makes it possible to provide these data, and to help us to analyse the impact of predefined metrics on a future process.

In this way, a discrete event simulation could be used to imitate a future process, to provide some data to perform statistical analysis, and thus, to provide recommendations for RFID implementation. The recommendations initially aimed to determine the RFID reader layout and to show the profits in terms of CTQs (for example, the lead time and inventory).

\subsection{Toward discrete event simulation}

While spreadsheet and queuing models are useful for answering basic questions about manufacturing systems, discrete event simulation models are often needed to answer more specific questions about how a complex manufacturing system will perform (Chance, (1996)). In general, a simulation is a practical methodology for understanding the high-level dynamics of a complex manufacturing system. According to Yücesan and Fowler, (2000), a simulation has several strengths, including: 
- Time compression: the potential to simulate years of real system operation in a shorter time.

- Component integration: the ability to integrate complex system components to study their interactions.

- Risk avoidance: hypothetical or potentially dangerous systems can be studied without the financial or physical risks that may be involved in building and studying a real system.

- Physical scaling: the ability to study much larger or smaller versions of a system.

- Repeatability: the ability to study different systems in identical environments, or the same system in different environments.

- Control: everything in a simulated environment can be precisely monitored and exactly controlled.

Isermann et al., (1999) have distinguished three different types of real-time simulation methods (see Figure 4):

- The real process may be operated using the simulated control system employing hardware other than the real hardware. This is also called control prototyping.

- The simulated process is run using the simulated control system in real time. This may be required if the final hardware is not available, or if a design step before the hardware-in-theloop simulation is considered.

- The simulated process can be operated with the real control hardware. This is called hardware-in-the-loop simulation.

In our proposed approach, only hardware-in-the-loop simulation and software-in-the-loop was considered.

\section{Methodological approach to design and validate a PDS based on six sigma methodology and discrete event simulation}

The six sigma method is used to capture a user's requirements related to a PDS and define the CTQ metrics, which are supposed to be the foundations of the design and simulation phases. Figure 5 shows the generic guidelines and the chosen tools composing our proposed approach. The define and measure phases focused on capturing customer requirements based on a refinement process. The analyse phase aimed to define the pilot and requirement functions of the PDS using a Pugh matrix or Quantity Functions Deployment (QFD). The design and verify phases were based on simulations to design a candidate PDS solution and to verify real control using an emulation model.

\subsection{Define}

The aim of this phase consisted of selecting a team whose members brought expertise to the study, defining a project charter to specify our mission, defining an SIPOC (diagram of Suppliers, Inputs, Process parameters, Outputs, and Customers) to define the end process and goals, and defining a voice of the customer survey (VOC) to understand the CTQ. (See Figure 5)

\subsection{Measure}

The objective of this step was to translate the VOC to CTQ, or other metrics that could be measured. First, we grouped the large volume of improvement ideas that came from brainstorming processes to treat the subassemblies more easily. The complexity of the project decreased, and the modelling process was simplified. Among the variety tools used to match this goal, an affinity diagram is a tool 
that gathers a large amount of language data (ideas, opinions, and issues) and organizes them into groupings based on their natural relationships.

The resulting idea subassembly should be classified to obtain more critical metrics for the customer. In this way, the Kano Model (Jacobs, (1999)) of customer satisfaction divides the product attributes into three categories: threshold (must be), performance (more is better), and excitement (delighter). The last operation concerns the refinement of customer CTQs using a CTQ tree diagram to move from qualitative metrics to quantitative metrics. In fact, in such a project, quantitative metric must stand out to drive simulation scenarios.

\subsection{Analyse}

To analyse the CTQs from the measure phase, several tools are proposed by the six sigma methodology, such as the quality function deployment (QFD) or, more simply, the Pugh matrix (Pugh, (1996)). The Pugh matrix was designed as an approach for evaluating multiple options against each other relative to a baseline option. In our context, this tool can help select the pilot and the implementation concepts. The QFD is used to translate customer requirements to engineering specifications. It is a link between customers, design engineers, competitors, and manufacturing. In this phase, the QFD is used to identify the most important functions to be implemented in the system control. In our project, these most important functions were known (synchronizations functions), and consequently the QFD was not used.

\subsection{Design (software-in-the-loop)}

Software-in-the-loop simulation was used to design the PDS control. This method consisted of coupling control models with plant models to evaluate the accuracy of the proposed control rules. In the area of production system modelling, there is a consensus on the architecture of benchmarking environments that puts emphasis on modularity between the control system (C) and an emulated manufacturing process $(\mathrm{P})$ to provide practitioners with the capability to share and compare test cases. In the particular context of PDS control, we proposed the systematic modelling of El Haouzi et al., (2007):

- Elementary physical entities that only focus on transformation on the product flows, i.e., the manufacturing process.

- Control heuristics and algorithms that represent the centralized decisions.

- Local decisional entities having both physical and logical behaviour.

The problem of PDS design is to identify which, when, and where product information and events can contribute to improve test performance indicators given by the CTQs. Our proposed modelling constructs provide the ability to simulate interactions between control, product information/events, and physical processes, and consequently, to evaluate many PDS scenarios.

\subsection{Verify (hardware-in-the-loop)}

Hardware-in-the-loop simulations consist of validating the behaviour of a real system within its emulated environmental context. The emulation runs on a controller board that mimics the target hardware. In the context of control validation, the main advantage is that the validation can be carried in a virtual platform without using the real physical system. This decreases the time of development and implementation.

The development of PDS control can be based on various technologies stemming from artificial intelligence, such as multiagents, or distributed architecture, such as Web applications. Consequently, hardware-in-the-loop simulation requires developing communication interfaces between the selected technology and emulation models. 


\section{Application}

\subsection{Define}

In this phase, the perimeter of the application was not restricted to a particular process of the company, but was extended to all processes that had a direct impact on the assembly shop floor. Table 1 shows a macroscopic view of the SIPOC relative to the Trane Company assembly shop floor organization. The detailed SIPOC is not presented here given the large volume of input and output requirements. In the measure phase, the most important outputs are throughout the affinity diagram.

\subsection{Measure}

Table 2 shows the affinity diagram that was based on the SIPOC and VOCs of the customer outputs. Improvement ideas were translated to CTQ metrics and classified into three categories to launch the Kano model.

In this study, the Kano model showed that the most critical CTQs were the lead time and the cost (see the "Must Be" column in Figure (6)).

The CTQ tree diagram shows that we can classify all of these metrics into three families: the metrics related to the time (lead time), the quality, and the cost. These three families are not independent, and thus, the metrics relating to quality can be measured in terms of cost resulting from a wrong setting, or from the time spent to have good product information.

To decrease the lead time by optimizing the various flows of assembly lines and feeders, an initial answer was to manage the flows in a pull manufacturing system based on DFT concepts. However, to better synchronize the assembly lines and the feeders, we had to build inventories at the decoupling points (IPK). This fact increases the cost of immobilization and handling. The goal of our study was to find the trade-off between cost reduction and time delay optimization using simulation scenarios.

\subsection{Analyse}

The objective of this phase was to select the pilot and the implementation concept based on the results of the "measure" phase. On the one hand, knowing that all the Trane Company assembly lines are standardized according to DFT rules, the pilot will be selected according to three criteria:

- (A) The pilot must show the maximum of CTQ impact on the shop floor system.

- (B) The pilot should not be complex. The concept of complexity is always debatable and not easily measurable. Nevertheless, we proposed some logical and intuitive rationale rules: the number of pilot workstations, the number of feeders, or the number of fed assembly lines if the pilot is a feeder.

- (C) Whether an existing pilot process or not, the aim was to realize a study without the financial or physical risks that may be involved in building and studying a real system.

The selection was performed using a Pugh matrix on which the various assembly lines and feeders were selected according to the three criteria and weighting factors defined by the team members. 
On the other hand, the goal of the concept selection was to provide a macroscopic view of the implementation design. For this, several tools are proposed by the six sigma methodology: the quality function deployment (QFD), or more simply, the Pugh matrix.

In this step, we chose a pilot called PilotAB. The pilot is composed by an assembly line "a" with four workstations (ws1, ws2, ws3, and ws4) and the feeder "f" with four workstations (wsf1, wsf2, wsf3, wsf4). This feeder must satisfy the need of another plant, Plant site B (managed with a basic Kanban system). We must satisfy by priority the needs of Plant site A and satisfy all the Kanban requirements per day for Plant site B. Note that the other feeders are ignored in this case; consequently, the only synchronization problem to solve is between the feeder "f" and the assembly line "a" at the IPK point.

Nowadays, the synchronization of an assembly line and its feeders is realized using the shop packet. These documents (line and feeders) are edited and scheduled in the same way. To summarize, the factory is considered a black box, where the only information available is the projected schedule of the assembly line and its expected components. Being sure that the correct component is manufactured at the correct moment is the operator's responsibility. Concerning feeder management, component manufacturing is anticipated to make sure that the assembly line does not stop because of a missing component. This fact creates a large stock level. This type of management is the opposite of the main objective of DFT, which is to decrease inventory.

The expected functions that a PDS must perform are:

- Manufacture will be to order. The product arrival in a particular process in the assembly line triggers a signal of the component manufacturing. This fact decreases inventory because of the large anticipation time.

- The manufacturing information related to the feeder trigger corresponds exactly with the expected component. Consequently, the production quality will improve.

The remaining question is, "What will be the best moment in the assembly line for sending a manufacturing signal to the feeder to be sure that the expected component arrives at the right moment, and to ensure that this type of control does not involve delays to the assembly lead time?"

To answer this question, we carried out various simulation scenarios to identify the moment that is pertinent for sending this signal and for evaluating the profits in terms of lead time and inventory level.

\subsection{Design: software-in-the-loop}

\subsubsection{Resulting architecture}

As discussed in Section 4, discrete event simulation makes it possible to simulate the behaviour of assembly lines and feeders, and the statistics generated give the engineer good indicators to integrate an effective system of traceability and control. In this way, several software packages exist (e.g., Arena, AuroMod, Modelica, and Witness). Our choice was Arena, widely used in the industrial and academic fields (Al-Ahmari and Ridgway, (1999), Perera and Liyanage, (2000), Kovács et al., (1999)). Arena models were developed without any information and decision rules. Three models are necessary to represent the feeder and the two assembly lines in the two production sites (see Figure 8). Thanks to Arena, two types of results were provided: (1) physical flow animation and (2) statistic sheets useful for planning optimization.

\subsubsection{Simulation process: scenario analyses}

In the first phase of the simulation process, the flow of the "PilotAB" factory was defined and data estimates were established by experts. Table 3 shows the major parameters for the simulation model, which is a standard MPS. We obtained the order priorities, the references, the number of components 
waiting from Feeder "f", and the operational times of the four assembly line workstations. A similar table provided the operational times of the feeder components.

In the second step, the various scenarios of the readers' implementation were defined. In Hypothesis $1, \mathrm{H} 1$, the reader is implemented in Workstation ws1, i.e., the manufacture signal is sent to the feeder at the beginning of assembly line "a". In Hypothesis 2, $\mathrm{H} 2$, the reader is implemented at Workstation 2 "ws2". In Hypothesis 3, H3, the reader is implemented at Workstation 3 "ws3.

To summarize the most important points in our statistical analysis, Figure 10a shows the lead time in minutes per finished component for the feeder, and Figure 10b shows the lead time in minutes per finished product. A comparison between the different hypotheses was only considered when the production line reached its steady functional state (Zone A in both Figures 10a and 10b). Concerning the assembly line, there was no difference in lead times between $\mathrm{H} 1$ and $\mathrm{H} 2$, and they both satisfy the needs of Plant sites A and B.

Concerning the feeder, Figure 10a shows that the waiting time for the feeder was minimal for H2. This can be explained by the fact that a too important anticipation of the trigger tended to overload the IPK capacity between the feeder and assembly line and the product arrival frequency (consequently triggering a signal in $\mathrm{H} 1$ ).

To conclude, H2 showed better results for both lead time and inventory metrics. Hypothesis 3 was purposely omitted, because when the first product arrived at Workstation ws4, it waited about $60 \mathrm{~min}$ before obtaining its 14 components (shortage case).

5.5 Verify: hardware-in-the-loop simulation

\subsubsection{General architecture of the emulation process}

In this phase, we used the same emulation model developed using Arena. The control system was composed using a communication system connected with Oracle and the ERP (manufacturing orders and information traceability) and a user interface to help the human operators in their work by displaying the method sheet and the bill of materials (Figure 11).

\subsubsection{Description of the control system}

The control system was developed as a Web application using ASP.Net and VB.Net. Concerning the pilot, the industrial aim was to produce "fans" assembled at different workstations. To ensure product traceability and to control material flow between the two sites, the Web application was connected to an Oracle database.

The operator screen (see Figure 12) contained the following information:

- Information specifying the demand (e.g., work order number, item part number, and quantity).

- Bill of materials (data come from the ERP).

- Operation Manufacturing Sheet (OMS), describing the operations.

- Information zones useful in case of breakdown in bar code or RFID tag scanning.

\subsubsection{Communication interface}

The Web application sends the OF parameters to Arena, which creates entities with the received attributes. Then, the emulation model (also in Arena) "emulates" the item "bar code scan" and sends the scanned information via a socket (e.g., Trane Company reference number and work order number). 
While the Arena data is being received, the operator work centre can send a request (via a XMLHttpRequest object), and this request is stored by a control system in the database. As soon as the Web application is launched, it sets up a server socket using SocketClient DLL. This socket is the only communication path between the Arena models and the control system, and the XMLHttpRequest objects are the only communication between the work centres and the control system (see Figure 13).

\section{Discussion}

The question of the model's validity remains, and cannot be ignored. It seems widely accepted in the simulation community that models or modelling approaches cannot be fully validated. However, it makes sense to have some form of quality assurance to ensure that a model is fit for its intended purpose. The simulation model presented above was validated in two ways. In the first way, the expert team used the Arena interaction module to help them run the simulation step-by-step to validate the input data. In the second way, because of the standardization of all the Trane Company processes, the generic library constructs were validated on existed assembly lines, where we compared actual data with the simulation results with a confidence interval of $10 \%$. The remaining question is, "If RFID is used to implement new decision-making processes, does the preceding confidence interval still remain the same?"

\section{Conclusions}

In this paper, we have defined an approach where six sigma methodology is combined with two types of discrete event simulation: a software-in-the-loop simulation to progressively build a PDS control and a hardware-in-the-loop emulation to validate the real PDS control before implementation in a plant. The use of the full approach in a case study was discussed. The results can help managers in the Trane Company validate PDS profitability and feasibly. Compared with the same methodological approaches for building simulation models, such as the ASDI (Analyze, Specification, Design, and Implementation) approach, our approach is particularly interesting because of the possibility of managing project quality criteria. Effectively, these approaches can be used to build simulation models for complex industrial systems through the modular decomposition of the system being studied. However, it does not provide solutions or approaches for selecting the performance criteria of those systems. Moreover, this modular decomposition does not take into account any newly distributed architecture (Chabrol et al., (2005)).

The choice of using the software-in-the-loop simulation to design the PDS application decreased the time and the cost of this study. Hardware-in-the-loop enabled us to validate the real control application in a low cost and safe environment. The main weakness of our approach was that the time schedule periods were different in the emulation model, "Arena", and the Web application. The synchronization between the different models needs to be ensured on a case-by-case basis. Future work is aimed at improving the time management between the emulation model and a real control system using a more standard approach, such as High Level Architecture (IEEE, (2003)).

\section{Bibliography}

Vollman, T., Berry, W., Whybark, D. 1988. Manufacturing Planning and Control Systems, Irwin,. Costanza J., Just-In-Time manufacturing excellence John Costanza Institute of Technology Inc.; 3rd edition (September, 1996) ISBN B0006ENXLI.

McFarlane, D., Sarma, S., Chirn, J.L., Wong, C.Y., Ashton, K. 2003: Auto id systems and intelligent manufacturing control. Engineering Applications of Artificial Intelligence, 16(4): 365-376.

Challenges to global RFID adoption N.C. Wu, M.A. Nystrom, T.R. Lin, H.C. Yu Volume 26, Issue 12, December 2006, Pages 1317-1323

EPCglobal Inc., 2005. EPCTM Radio-Frequency Identity Protocols Class-1 Generation-2 UHF RFID Protocol for Communications at 860-960 MHz, v1.0.9, 31 January 2005. EPCglobal NetworkTM 
ISO/IEC 18000, "Information technology - Radio frequency identification for item management", 2004. www.iso.org

Cavalieri, S., Macchi, M., Valckenaers, P. 2003: Benchmarking the performance of manufacturing control system: design principles for a web based simulated testbed. Journal of Intelligent Manufacturing 14: 43-58.

Valckenaers P., Cavalieri S., Saint Germain B., Verstraede P., Hadeli, Bandinelli, R., Terzi, S., Van Brussel, H. 2006: A benchmarking service for the manufacturing control research community. Journal of Intelligent Manufacturing 17, 667-679.

Anbari, F.T. 2002: Six Sigma Method and Its Applications in Project Management, Proceedings of the Project Management Institute Annual Seminars and Symposium [CD], San Antonio, Texas. Oct 3-10. Project Management Institute, Newtown Square, PA, USA.

Harry, M., Schroeder, R., 2000: Six-sigma: the breakthrough strategy revolutionizing the world's top corporation. Doubleday, New York, NY, USA.

Hoerl, R.W. 2001: Six sigma black belts: what do they need to know. Journal of Quality Technology 33(4), 391-406.

Hoon, K Y., Anbari F T. 2006: Benefits, obstacles, and future of six sigma approach, Technovation 26 708-715.

Chance, F., Robinson, J., and Fowler, J. 1996: "Supporting manufacturing with simulation: model design, development, and deployment", Proceedings of the 28th conference on Winter simulation, Coronado, California, United States Pages: 114 - 121, ISBN:0-7803-3383

Yücesan, E., and Fowler, J. 2000: "Simulation Analysis of Manufacturing and Logistics Systems", Encyclopedia of Production and Manufacturing Management, Kluwer Academic Publishers, Boston, USA, P. Swamidass ed., 687-697.

Isermann R., Schaffnit J., Sinsel S. 1999: Hardware-in-the-loop simulation for the design and testing of engine-control systems. Control Engineering Practice, 7 643-653.

Jacobs R., Evaluating Satisfaction with Media Products and Services: An Attribute Based Approach, European Media Management Review, winter 1999.

Pugh S. 1996: "Creating Innovative Products Using Total Design: The Living Legacy of Stuart Pugh", in Clausing, D., Andrade, R. (Eds), Addison-Wesley, Reading, MA, USA.

El Haouzi H., Thomas A., Pétin J.-F. Contribution to reusability and modularity of Manufacturing Systems Simulation Models: application to distributed control simulation within DFT context, International Journal of Production Economics 112, 1 (2008) 48-61.

Al-Ahmari, A.M.A., Ridgway, K. 1999: An integrated modelling method to support manufacturing system analysis and design. Computers in Industry 38(1999), 225-238.

Perera T., and Liyanage K. 2000: Methodology for rapid identification and collection of input data in the simulation manufacturing systems. Simulation Practice and Theory 7, 645-656.

Kovács G.L., S. Kopácsi, J., Nacsa, G., Haidegger, and Groumpos, P. 1999: Application of software reuse and object-oriented methodologies for modelling and control of manufacturing systems. Computers in Industry Volume 39, Issue 3, July 1999, Pages 177-189.

Chabrol M., Sarramia D., Tchernev N. 2005: Urban traffic systems modelling methodology. International Journal of Production Economics. Volume 99, Issues 1-2, January-February 2006, Pages 156-176

IEEE Recommended Practice for High Level Architecture (HLA) Federation Development and Execution Process (FEDEP). IEEE Standard 1516.3, April 2003. IHS Standards Store. 


\begin{tabular}{|l|l|}
\hline \multicolumn{1}{|c|}{ Suppliers/customers } & \multicolumn{1}{c|}{ Link to assembly shop floor (control system) } \\
\hline Maintenance & Equipment capacity indicators \\
\hline Quality & Quality measurements/product and operator certification \\
\hline Manufacturing & Shop floor follow-up \\
\hline Engineering/Process & Shop floor organization \\
\hline Supply Chain & Material flow schedules \\
\hline Engineering/Product development & Product specifications (BOM, method sheets) \\
\hline Safety & Covers safety aspects of equipment and human operators \\
\hline
\end{tabular}

Table 1. Actors (suppliers /customers) directly linked to the Trane Company shop floor.

\begin{tabular}{|c|c|c|c|c|}
\hline Customers & $\begin{array}{c}\text { Improvement/ } \\
\text { profitability (Customer } \\
\text { needs) }\end{array}$ & $\begin{array}{c}\text { RFID infrastructure Contribution } \\
\text { (How?) }\end{array}$ & CTQ & $\begin{array}{c}\text { Grade } \\
\text { 3=Must Be } \\
2=\text { More Is Better } \\
\text { 1=Delighter }\end{array}$ \\
\hline \multirow[t]{4}{*}{ ENGINEERING } & $\begin{array}{l}\text { Identify and remove the } \\
\text { bottlenecks }\end{array}$ & Analysis of the real lead times & Real lead times Vs SOE times & 3 \\
\hline & $\begin{array}{l}\text { Speed up the modification } \\
\text { process }\end{array}$ & Disponibility of data in real-time & $\begin{array}{l}\text { Non-updated permanent } \\
\text { drawings rate }\end{array}$ & 2 \\
\hline & Automate the processes & Send informations to the equipments & $\begin{array}{l}\text { Labor time \& non-conformities } \\
\text { costs due to wrong setting }\end{array}$ & 2 \\
\hline & $\begin{array}{c}\text { Track the special orders \& } \\
\text { prototypes }\end{array}$ & $\begin{array}{c}\text { Have a quick access to the location } \\
\text { data }\end{array}$ & Reliability of SOE Times & 1 \\
\hline \multirow[t]{3}{*}{ MANUFACTURING } & $\begin{array}{l}\text { Reduce cost of data } \\
\text { collection }\end{array}$ & Use hand-held devices \& readers & non-added value time & 3 \\
\hline & $\begin{array}{l}\text { Reduce cost of quality } \\
\text { controls }\end{array}$ & Digitize the controls & quality control time & 3 \\
\hline & $\begin{array}{l}\text { Reduce the time for } \\
\text { searching the right doc }\end{array}$ & Display automatically the doc & Doc display time & 3 \\
\hline \multirow[t]{5}{*}{ QUALITY } & $\begin{array}{l}\text { Ease the tracking of the } \\
\text { critical components }\end{array}$ & Have a digitized Log Sheet & Log Sheet filling time & 3 \\
\hline & $\begin{array}{l}\text { Verify assembled } \\
\text { components Vs BOM }\end{array}$ & Get as-built BOM for each product & Assembly errors cost & 3 \\
\hline & $\begin{array}{l}\text { Disponibility of the quality } \\
\text { data }\end{array}$ & Have a centralized database & Decentralized metrics quantity & 2 \\
\hline & $\begin{array}{c}\text { Deliver meaningful } 6 \text { Sigma } \\
\text { results }\end{array}$ & Make the data analysis easier & Reliability of the recorded data & 2 \\
\hline & Ease the on-site repair & Have distributed information & Time to on site reparir & 1 \\
\hline \multirow[t]{3}{*}{ SUPPLY CHAIN } & $\begin{array}{l}\text { Manage the customer } \\
\text { orders in real-time }\end{array}$ & $\begin{array}{l}\text { Have a quick access to the location } \\
\text { data }\end{array}$ & Unit tracking time & 3 \\
\hline & $\begin{array}{l}\text { Improve accuracy of } \\
\text { inventory }\end{array}$ & Have the right consumption in real-time & Inventory accuracy rate & 3 \\
\hline & Minimize the travellers & Display the documentation on line & $\begin{array}{c}\text { Travellers preparation time / } \\
\text { Sheets quantity }\end{array}$ & 2 \\
\hline
\end{tabular}

Table 2. The affinity diagram showing the CTQ and RFID opportunities.

\begin{tabular}{|c|c|c|c|c|c|c|c|}
\hline Prionity & reference & Component Hurnber & $\mathrm{H}^{*}$ Ordes: & thrsl & $t w 2$ & $t w 53$ & tws 4 \\
\hline 1 & $\mathrm{C2}$ & 14 & 10 & 60 & 408 & 40,8 & 75,48 \\
\hline 2 & $\mathrm{Cl}$ & 14 & 20 & 55 & 408 & 41,82 & 73,44 \\
\hline 3 & $\mathrm{D}$ & 12 & 30 & 37 & 64,26 & 27,54 & 69,36 \\
\hline 4 & $\mathrm{Cl}$ & 14 & 40 & 60 & 40,8 & 40,8 & 75,48 \\
\hline $\begin{array}{l}5 \\
6\end{array}$ & $\begin{array}{c}\mathrm{Cl} \\
\mathrm{D}\end{array}$ & $\begin{array}{l}14 \\
12\end{array}$ & $\begin{array}{l}50 \\
60\end{array}$ & $\begin{array}{l}55 \\
37\end{array}$ & $\begin{array}{c}40,8 \\
64,26\end{array}$ & $\begin{array}{l}41,82 \\
27,54\end{array}$ & $\begin{array}{l}73,44 \\
69,36\end{array}$ \\
\hline 7 & $\mathrm{C2}$ & 14 & 70 & 60 & 40,8 & 40,8 & 75,48 \\
\hline
\end{tabular}

Table 3. Master of production planning (MPS). 


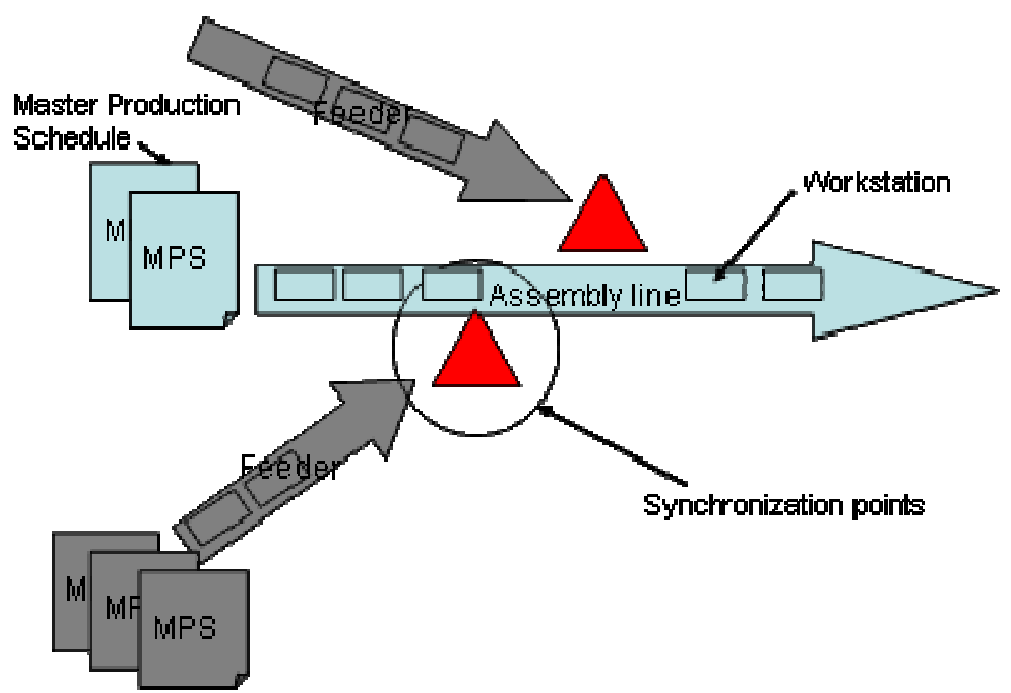

Figure 1. An assembly line shop floor structure.

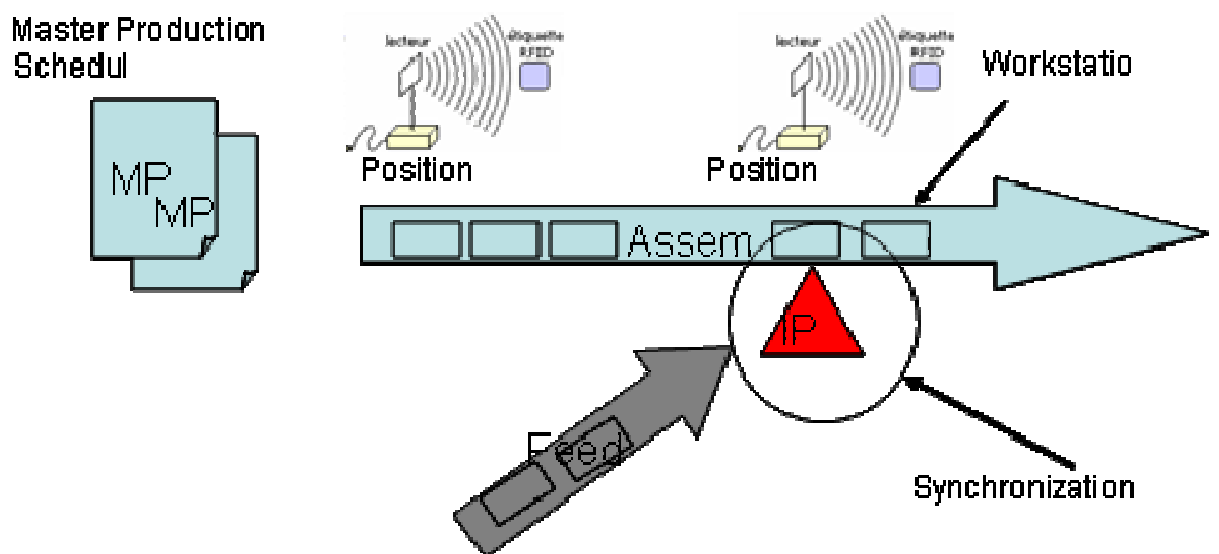

Figure 2. DFT structure with a discrete RFID layout.

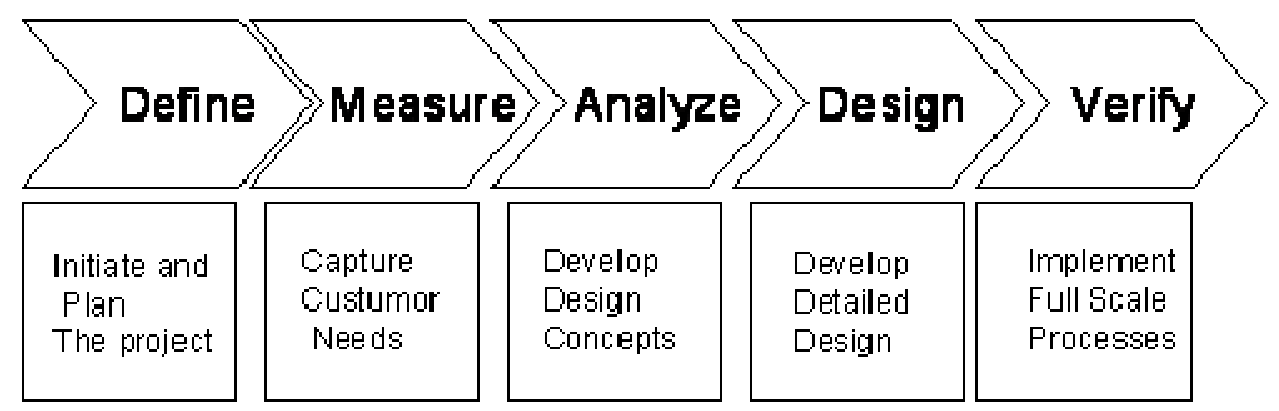

Figure 3: Design for six sigma phases. 


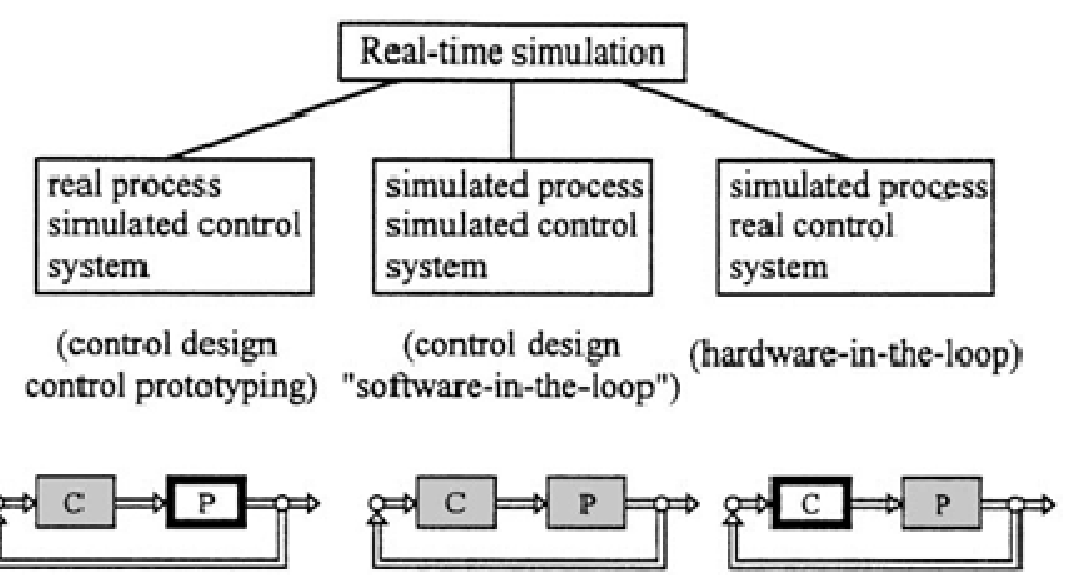

Figure 4. Classification of a real-time simulation (Isermann et al., (1999)).
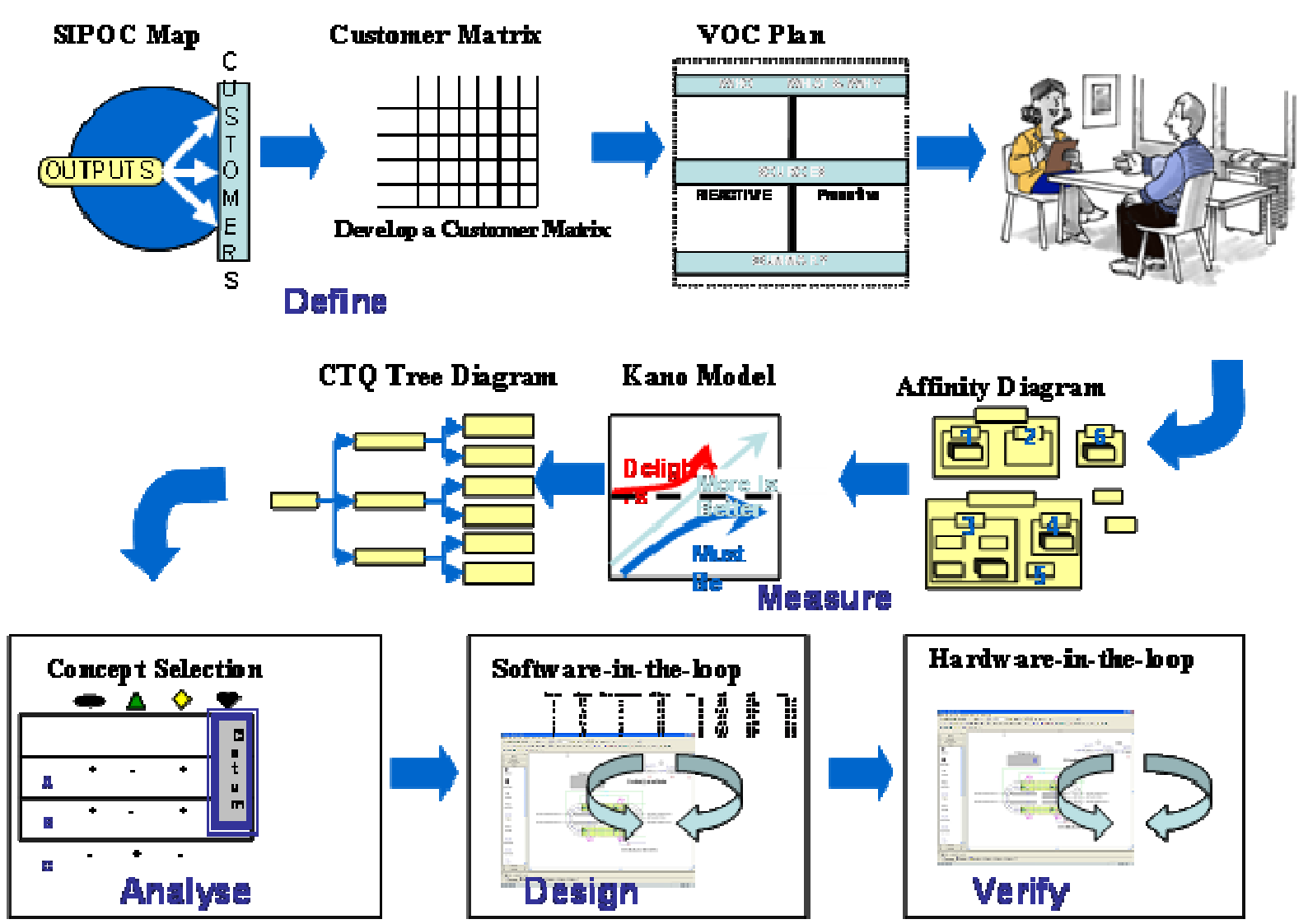

Figure 5. Design and validation of a product-driven control system.

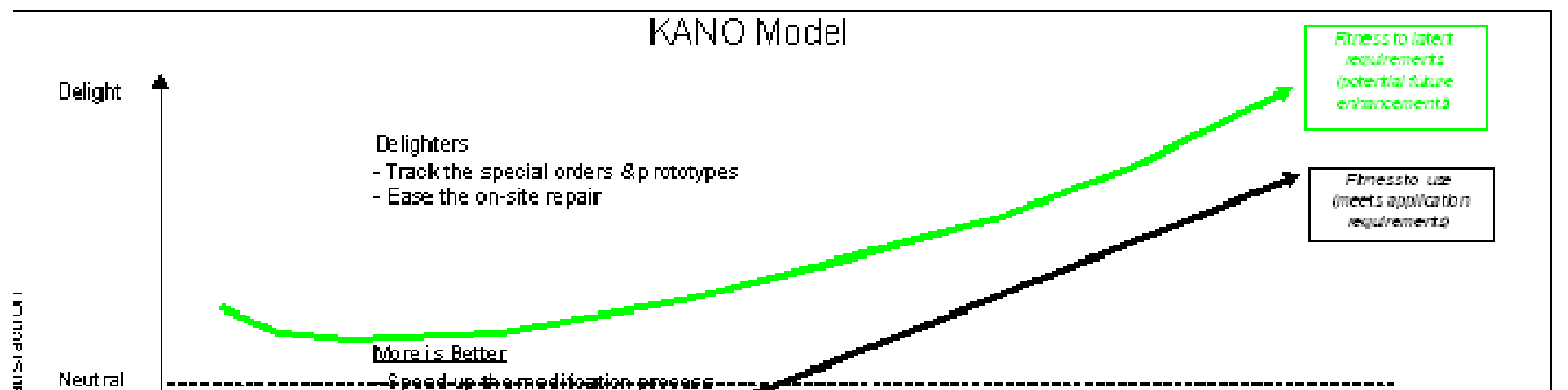


Figure 6. The Kano model.

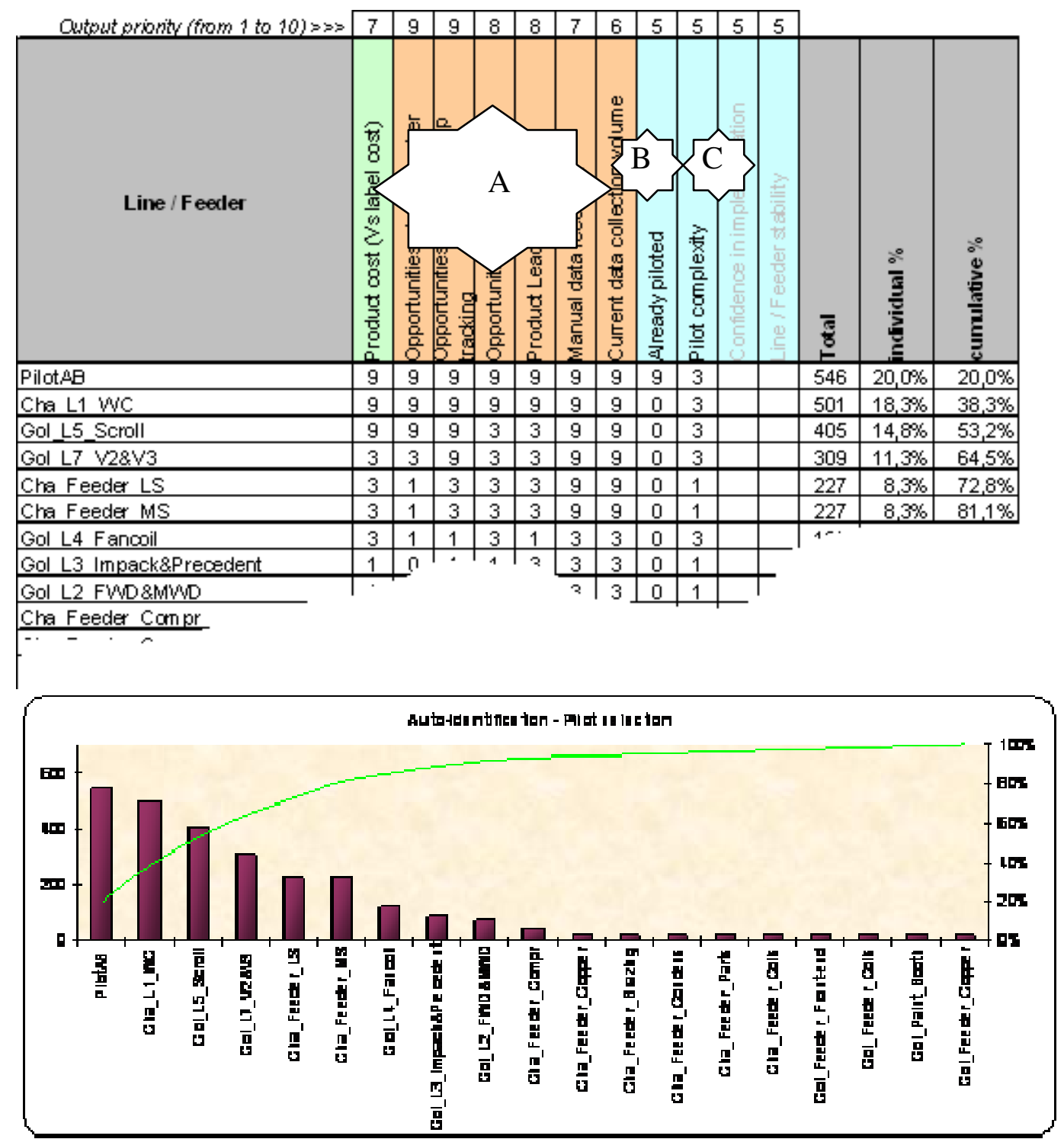

Figure 7. Pugh Matrix and resulting Pareto classification. 


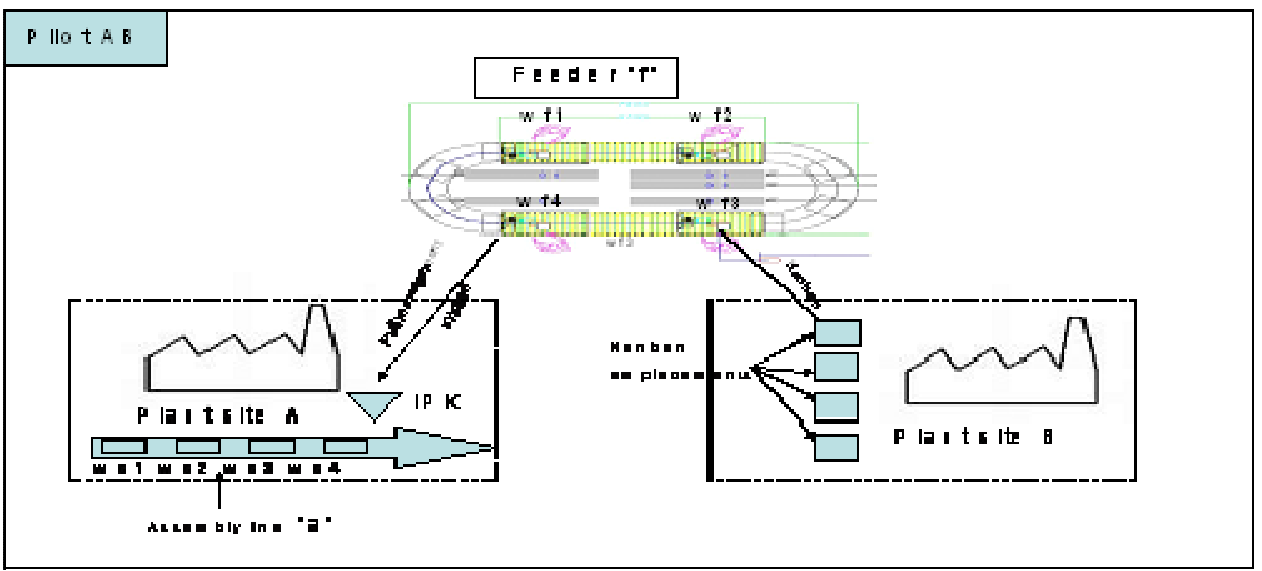

Figure 8. The Pilot $\mathrm{AB}$ view.
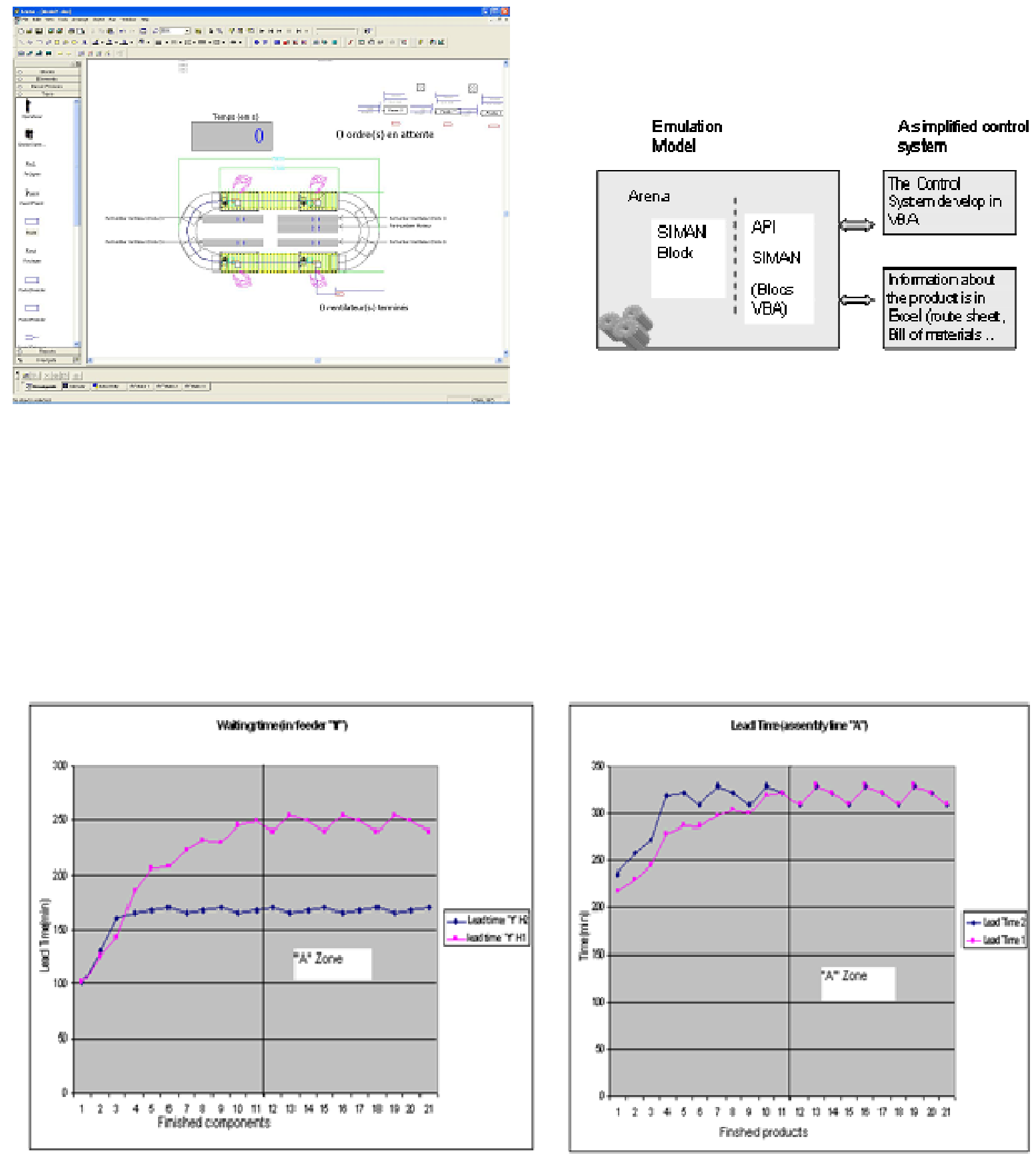
Figure 10a. Analysis of the feeder.

Figure 10b. Analysis of the assembly line Figure 9. The simulation model.

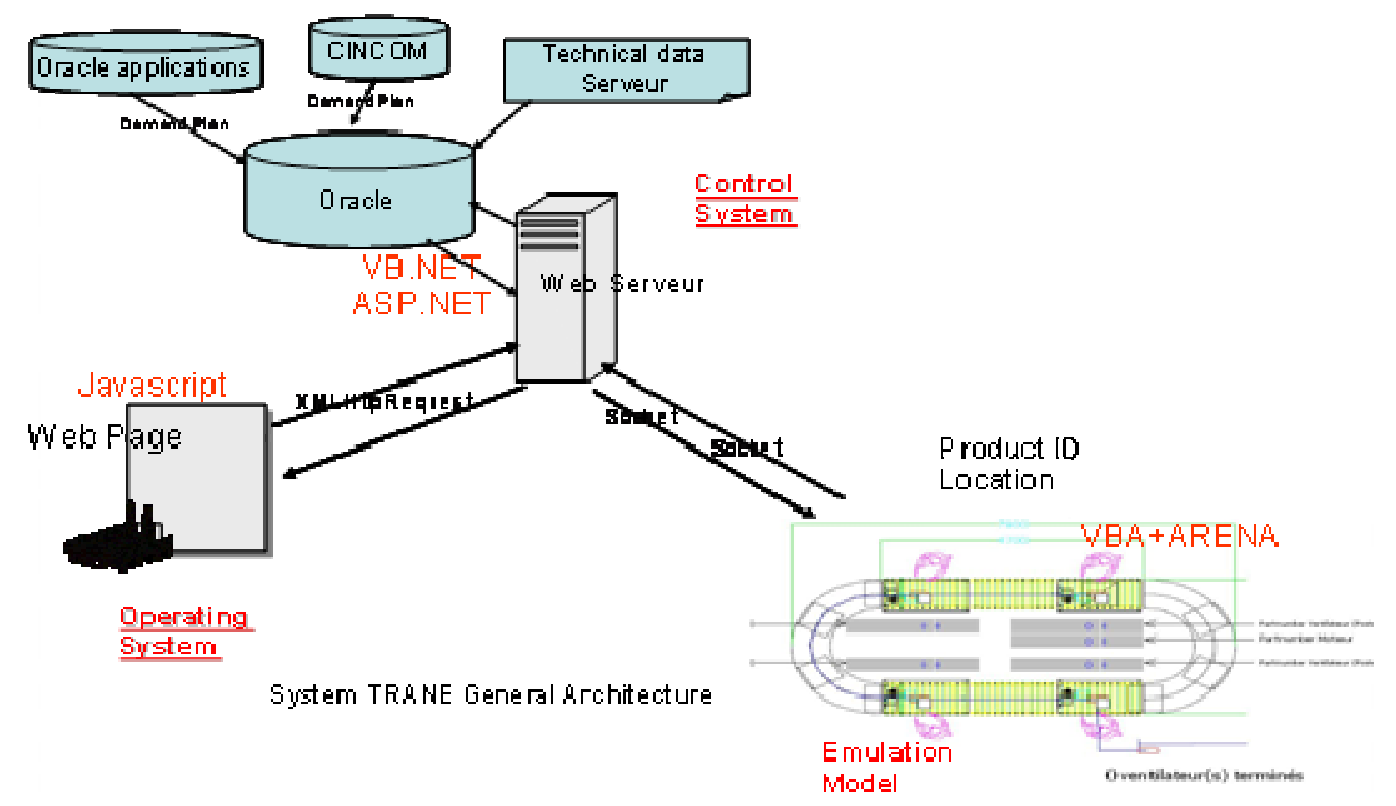

Figure 11. General architecture of the emulation test-bed.

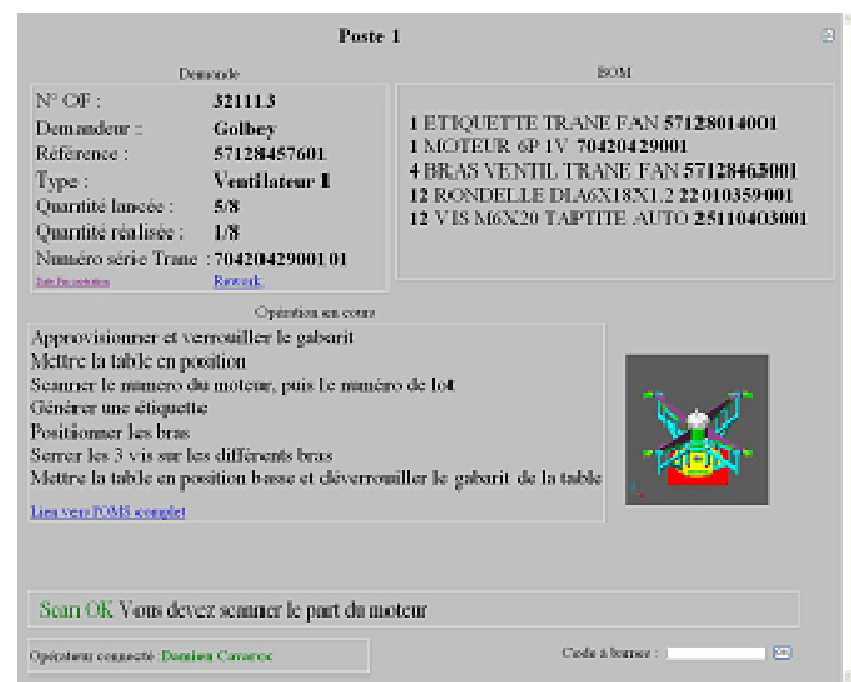

Figure 12. Operating system user interface.

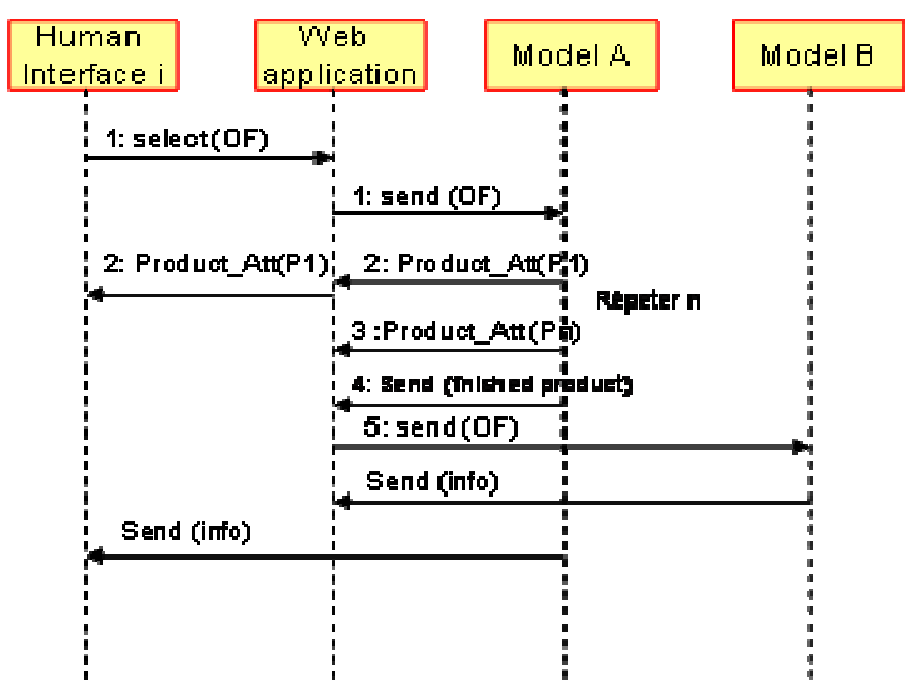


Figure 13: A UML diagram for the communication protocol. 